http://jmscr.igmpublication.org/home/ ISSN (e)-2347-176x ISSN (p) 2455-0450 crossref DOI: https://dx.doi.org/10.18535/jmscr/v8i4.47

\title{
Congenital Heart Disease in Children - A Tertiary Care Centre Experience
}

\section{Authors \\ Dr Jnanindra Nath Behera ${ }^{1}$, Dr Sunil Sharma ${ }^{2}$, Dr Sumit Kumar ${ }^{3 *}$, Dr Amlan Khatua ${ }^{4}$, Dr Bichitra Nanda $\mathrm{Sa}^{5}$}

${ }^{1}$ Professor \& HOD, Department of Pediatrics, Veer Surendra Sai Institute of Medical Sciences and Research, Burla, Sambalpur, Odisha

${ }^{2}$ Associate Professor, Department Of Cardiology, Veer Surendra Sai Institute of Medical Sciences and

Research, Burla, Sambalpur, Odisha

${ }^{3,4,5}$ Post Graduate Student, Department of Pediatrics, Veer Surendra Sai Institute of Medical Sciences and

Research, Burla, Sambalpur, Odisha

*Corresponding Author

Dr Sumit Kumar

\begin{abstract}
Background: CHDs are the most frequent lethal malformation, affecting about $1 \%$ of newborn and causing significant morbidity and mortality in infants. It responsible for $28 \%$ of all congenital birth defects.

Objective: To estimate the prevalence of Congenital heart disease among children (0-14 yrs) admitted in Department of Pediatric and to categorize them into various types of congenital heart disease with clinical presentation and investigations and to compare prevalence in Western Odisha with different other states of India.

Method: Patients of age between 0-14 years attending OPD and IPD of pediatric department with clinical signs and symptoms of CHD were examined for CHD. The suspected patients were further evaluated with chest $X$-ray and confirmed with echocardiography.

Result: Among total of 73,000 patients attended as outpatient and inpatient facilities at the Department of Pediatric, VIMSAR, Burla, 830 were clinically suspected as having heart disease among which 546 patients were identified as CHD, giving a prevalence of 7.4/1000 live births. About 434 (80.40\%) of patients were diagnosed with acyanotic, 102 (18.68\%) with cyanotic and complex heart disease 5 (0.91\%). The most common isolated CHD was found as VSD 270 (39.5) followed by ASD 150 (27.5) and PDA 100 (18.3) among acyanotic heart disease and TOF 38 (7) followed by TGA 15 (2.7) among cyanotic heart diseases.

Conclusion: The prevalence of CHD in this study was 7.41/1000 live births. VSD and TOF were common acyanotic and cyanotic CHD.

Keywords: Congenital heart disease, Children, Prevalence, Odisha.
\end{abstract}

\section{Introduction}

The congenital abnormalities and structural disorders in a newborn posing a major threats to their survival. The congenital heart disease is the most frequent occurring congenital abnormality in the children. ${ }^{1}$ It is responsible for $28 \%$ of all congenital birth defects ${ }^{2}$. Considering a prevalence of $9 / 1000$, about 1.35 million babies are born with CHD each year globally. ${ }^{3}$ 
Congenital heart disease (CHD) (con, together; genitus, born) is a group of gross structural abnormalities of heart that are present at birth. Malformations of the heart and circulation are not fixed anatomic defects that appear at birth but instead are anomalies in flux that originate in the early embryo, evolve during gestation, survive the dramatic circulatory alterations at birth, and change considerably during extrauterine life. ${ }^{4}$

The highest prevalence rate of congenital heart abnormality is happening in Asian countries. ${ }^{5}$ In the years 1999-2006, there has been reported 41,494 death due to congenital heart abnormalities, $48 \%$ of which was happened in the age less than one-year. ${ }^{6}$ In India, the prevalence of CHD is not uniform and varies from 0.8 to $5.2 / 1000$ patients in community based studies ${ }^{7,8}$ while the prevalence ranges between 3.9 and 26.4/1000 live births in hospital based studies in India. $^{7-12}$ In India, over 180,000 children are born with CHD every year with state wise variation and contribute to $10 \%$ of the present infant mortality. ${ }^{9}$ Nearly $1 / 3^{\text {rd }}$ of the CHD are critical requiring intervention in the 1st year of life. ${ }^{13}$ Moreover the burden of CHDs in India is enormous due to very high birth rate. This huge birth rate emphasises the importance of this group of disease. Inappropriate screening and notification of congenital cardiac diseases at birth have led to inadequate reporting of these cases. ${ }^{14,15}$

So, the prevalence studies of congenital cardiac disease are necessary to establish baseline rates, to know the geographical trends that may help to raise the awareness of early medical and surgical intervention. In western Odisha, there is a paucity of data of prevalence and pattern of CHD. Hence, this study was conducted to know the prevalence and pattern of CHD in this part of Odisha.

\section{Materials and Methodology}

This is a hospital based prospective observational study conducted in Dept. of Pediatrics VSSIMSAR Hospital, Burlafrom September 2017 to October 2019. Any patient of age between 0 days -14 years attended in OPD and IPD of
Department of Pediatrics having the signs and symptoms of congenital heart disease like shortness of breath, difficulty in feeding, excessive sweating, bluish discoloration of lips and tongue, failure to thrive, clubbing, palpitation, fainting, light headedness, rapid breathing, discrepancy in pulse, cyanosis, heart murmur, abnormal chest X-ray, swelling of face, abdomen and feet, chest and abdomen pain, and arrhythmias, etc were considered for the study.

A written and detailed consent was obtained from parents/legal guardians of every child. The demographic characters recorded in the respective case proforma. All the patients were classified according to the Modified Kuppuswamy's Socioeconomic Scale into upper middle, lower middle, upper lower and lower. ${ }^{16}$ A detailed history of poor feed, respiratory distress, bluish discolouration and cyanotic spell were taken and CHD was suspected. The cases were further examined for different signs by resident PGs and consultants on duty. Different signs like presence or absence of pallor, central cyanosis, clubbing, hyperdynamic precordium, parasternal heave, thrill, tachypnea, tachycardia, murmur and abnormal second heart sound were examined. Patients with a clinical diagnosis of heart disease were further evaluated with chest radiography, and the confirmation of the diagnosis was done using echocardiography. Echocardiographic evaluation was performed by senior cardiologists except in emergency hours. Examination was done as per standards laid down by the American Society of Echocardiography. ${ }^{17}$ Data validation and data cleaning were done manually by two separate persons not involved in the study. The descriptive data collected were analysed using SPSS v 25.0 (IBM, New York) software. Care had been taken to avoid duplication of the cases in the hospital during the study period. PDA in neonates $<2$ months of age were excluded from the study. 


\section{Study Flow Chart}

Total no patients examined for CHD in out-patient and inpatient ward during the study period

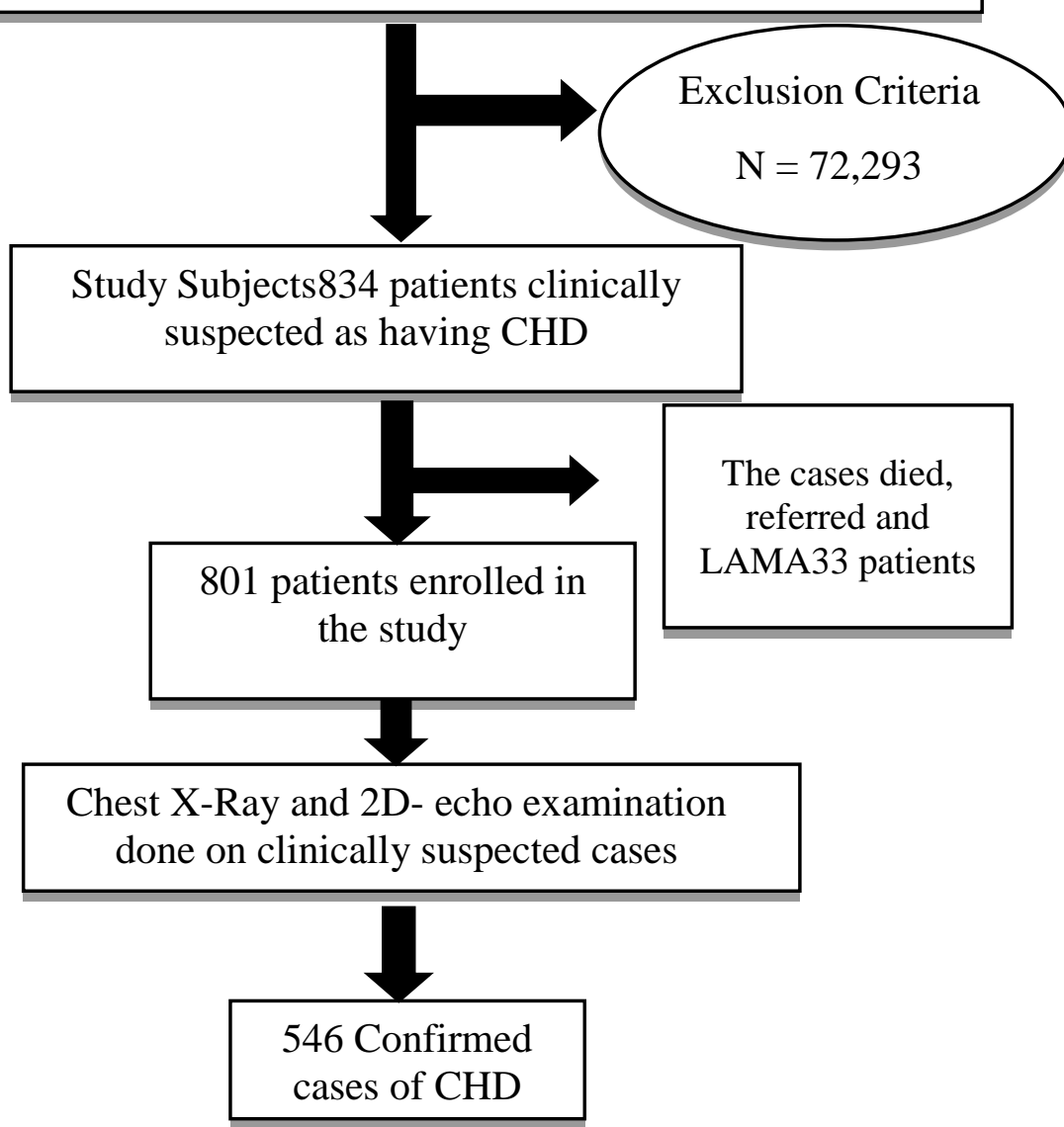

Figure: Flow diagram of study population

\section{Result}

A total of 546 subjects made up the study group. Of these males were 284(52\%) and 262(48\%) were females, giving a M:F ratio of $1.08: 1$. The Mean birth weight $(\mathrm{kg})$ was $1.83 \pm 0.48$ and mean SpO $2 \%$ of patients with oxygen through nasal cannula at the time of examination was $81 \% \pm 10$.

Social and demographic characteristics of the patients taken for study shows that majority of patients $(60.8 \%)$ were below age of 1 year. $13.4 \%$ patients presented below 1 month of age. In the present study CHD was more common in male (52\%) than female (48\%). Considering the socioeconomic status of the family of patients calculated by modified kuppuswamy scale ${ }^{16}$, most of the patients belong to upper lower socioeconomic class (Table1). Out of 546 diagnosed CHD patients, acyanotic heart disease constitutes $464(84.98 \%)$ and cyanotic $77(14.1 \%)$ and complex heart disease $5(0.91 \%)$. The most common symptom was tachypnea and tachycardia was the most common sign followed by abnormal $\mathrm{S}_{2}$ and murmur. The study shows relative frequencies of different acyanotic and cyanotic heart diseases as VSD (39.5\%) the most common CHD, followed by ASD (27.5\%), PDA (18.3\%), PS $(8.8 \%)$ and TOF (7\%) as seen in table 4. VSD was the most common among acyanotic CHD while TOF was the most common cyanotic CHD. Table 3 shows the CHD defect present in combination. VSD and ASD present in combination with various other type of $\mathrm{CHD}$ making it most prevalent type of CHD. 
Table 1: Social and Demographic Characteristics of the Study Participants

\begin{tabular}{lc}
\hline Variables & Frequency n (\%) \\
\hline Age groups & $73(13.4)$ \\
$0-1 \mathrm{M}$ & $124(22.7)$ \\
$1-6 \mathrm{M}$ & $135(24.7)$ \\
$6-12 \mathrm{M}$ & $133(24.4)$ \\
$1-6 \mathrm{Yr}$ & $81(14.8)$ \\
$6-14 \mathrm{Yr}$ & \\
Gender & $284(52)$ \\
Male & $262(48)$ \\
Female & \\
& \\
Socioeconomic status & $23(4.2)$ \\
Upper middle & $131(24)$ \\
Lower middle & $309(56.6)$ \\
Upper lower & $83(15.2)$ \\
Lower & \\
\hline
\end{tabular}

M: Months, Yr: Years

Table 2: Classification of CHD

\begin{tabular}{lc}
\hline Type of CHD & n (\%) \\
\hline Acyanotic & $434(80.40)$ \\
Cyanotic & $102(18.68)$ \\
Complex heart disease & $5(0.91)$ \\
\hline CHD: Congenital heart disease &
\end{tabular}

Table 3: Combined congenital defect

\begin{tabular}{lc}
\hline Nature of Defect & $\mathbf{n}(\boldsymbol{\%})$ \\
\hline ASD+VSD & $28(5.12)$ \\
ASD+PDA & $10(1.83)$ \\
ASD+PA & $6(1.09)$ \\
ASD+PS+PDA & $7(1.28)$ \\
VSD+PDA & $11(2.01)$ \\
VSD+DORV & $11(2.01)$ \\
VSD+PS+PDA & $5(0.91)$ \\
VSD+PS+TA & $6(1.09)$ \\
ASD+PS & $7(1.28)$ \\
VSD+PS & $6(1.09)$ \\
VSD+TA+PS & $6(1.09)$ \\
BAV+PS & $8(1.46)$ \\
BAV+PA & $6(1.09)$ \\
TA*+ AS & $3(0.54)$ \\
TAPVC+VSD & $5(0.91)$
\end{tabular}

CHD: Congenital heart disease VSD: Ventricular septal defect, ASD: Atrial septal defect, PDA: Patent ductus arteriosus, AS: Aortic stenosis, PA: Pulmonary atresia, TOF: Tetralogy of Fallot, , TGA: Transposition of great arteries, PS: Pulmonary stenosis TAPVC: Total anomalous pulmonary venous connection, COA: coarctation of aorta, TA: tricuspid atresia, EA: Ebstein anomaly, DORV: Double- outlet right ventricle, BAV: Bicuspid aortic valve, TA*: Truncus arteriosus, ECD: Endocardial cushion defect, HLHS: Hypoplastic left heart syndrome 
Table 4: Relative frequency of various type of CHD

\begin{tabular}{lc}
\hline Types of CHD & $\mathbf{n}(\%)$ \\
\hline VSD & $270(39.5)$ \\
ASD & $150(27.5)$ \\
PDA & $100(18.3)$ \\
AS & $11(2)$ \\
PA & $22(4)$ \\
TOF & $38(7)$ \\
TGA & $15(2.7)$ \\
PS & $48(8.8)$ \\
TAPVC & $5(0.9)$ \\
COA & $5(0.9)$ \\
TA & $12(2.2)$ \\
EA & $5(0.9)$ \\
DORV & $11(2)$ \\
BAV & $14(2.6)$ \\
TA* & $3(0.5)$ \\
ECD & $3(0.5)$ \\
HLHS & $2(0.4)$ \\
Complex heart disease & $5(0.9)$ \\
\hline
\end{tabular}

CHD: Congenital heart disease VSD: Ventricular septal defect, ASD: Atrial septal defect, PDA: Patent ductus arteriosus, AS: Aortic stenosis, PA: Pulmonary atresia, TOF: Tetralogy of Fallot, , TGA: Transposition of great arteries, PS: Pulmonary stenosis TAPVC: Total anomalous pulmonary venous connection, COA: coarctation of aorta, TA: tricuspid atresia, EA: Ebstein anomaly, DORV: Double- outlet right ventricle, BAV: Bicuspid aortic valve, TA*: Truncus arteriosus, ECD: Endocardial cushion defect, HLHS: Hypoplastic left heart syndrome

\section{Discussion}

There are few pre-existing supporting studied in India on the prevalence of congenital heart disease; which have found a wide range of prevalence mostly depending on the study type and populations. The generally accepted prevalence of CHD is 8 per 1000 live births. ${ }^{18}$ This study was a hospital based study, conducted to know the prevalence in Western Odisha. During the study period over 73127 were screened for the presence of CHD and 546 cases were diagnosed as cases of $\mathrm{CHD}$, giving a prevalence of 7.41 per 1000 live births.

CHD may be diagnosed virtually at any age. Most of the patients with CHD seek the medical facilities at very early age. As seen in table 1, 60.8 $\%$ of patients seek the medical facility below age 1 year including $13.4 \%$ of neonates. The age group of 6-14 years comprises only $14 \%$ of patients. However the actual age of presentation is less which was mostly ignored by parents or treated symptomatically at local hospitals. ${ }^{9}$ In this study, the gender distribution of cases showing male preponderance with male- to- female ratio of 1.08:1. However this dominance is not comparable with other study showing high difference between the male and female cases. Studies showed male and female ratio of 1.78:1 and 2.08:1, respectively. ${ }^{19,20}$

Studies has shown that a lower degree of maternal socioeconomic status is modestly associated with an increased risk of CHDs as many environmental factors and teratogen exposure to mother cause cardiac defect in foetus in intrauterine life. ${ }^{21}$ This study showed that most of the family belongs to the upper lower $(56.6 \%)$ status.

There is more prevalence of CHD in the newborn born prematurely. ${ }^{22} \mathrm{An}$ additional highly consistent finding is that infants with CHD are often born prematurely. ${ }^{23-25}$ Whether CHD, low birth weight, and prematurity are all co-outcomes of a common, underlying teratogenic influence such as maternal environmental exposure is plausible but as yet unknown. ${ }^{26,27}$ In this study the mean birth weight in $\mathrm{kg}$ is $1.83 \pm 0.48$ and the preterm babies were 314 (57.5\%). The proportion of complex heart disease in premature babies are more and mostly are life threatening. ${ }^{28}$

The clinical presentation of CHD varies according to the type and severity of the defect. ${ }^{11}$ Breathlessness $60 \%$, fatigue $54.8 \%$, cough $43.5 \%$, poor weight gain $41.7 \%$, recurrent chest infection $34.8 \%$, fever $28.7 \%$, feeding problem $26.1 \%$, 
palpitation $21.7 \%$, cyanotic spell $13 \%$, and convulsion $1.7 \%$ were the clinical presentations observed by Saxena $\boldsymbol{e t}$ al. ${ }^{28}$ In present study among the different clinical symptoms, breathlessness $483(88.4 \%)$ was the most common, followed by poor feeding $373(68.3 \%)$ and pallor $361(66.1 \%)$. Features suggestive of congestive cardiac failure were in both acyanotic and cyanotic heart disease.

In present study, as seen in table 4 out of 546 diagnosed CHD patients, acyanotic heart disease constituted $464(84.98 \%)$, cyanotic constitute 77 $(14.1 \%)$ and complex heart disease were $5(0.91)$. (Table 6) The use of 2D echocardiographic examination of patients increased the sensitivity of diagnosis and helped reveal minor lesions (small VSD, ASD, PDA, etc.) that might have remained unnoticed otherwise. VSD $270(39.5 \%)$ was the most common CHD, followed by ASD 150 (27.5\%), PDA $100(18.3 \%)$, PS $48(8.8 \%)$ and TOF 38 (7 \%). VSD was the most common acyanotic CHD while TOF was the most common cyanotic CHD. Most of the studies in the literature reported similar observation from India and other countries ${ }^{29}$ however, few studies reported a higher incidence of PDA compared to ASD. ${ }^{30-34}$

VSD was present in combination with a variety of other cardiac defects (PS, PDA, PFO, and BAV), showing a very high occurrence rate of this lesion. The combined CHD constitute a major portion. VSD $78(28.8 \%)$ of total VSD cases, ASD 58 $(38.6 \%)$ of total ASD cases, PDA $33(33 \%)$ of total PDA cases and PS $45(93.7 \%)$ of total PS case (Table 3).

Patients with atrial septal defect are usually asymptomatic in early age, and as they produce soft murmurs, these defects frequently do not lead to early diagnosis. Hence, the incidence of atrial septal defect in childhood actually underestimates the true incidence. The proportion of PDA in the preterm neonates with low birth weight is high. The preterm neonates of age below 2 months with diagnosis of PDA were excluded from the study. In this study PDA shows the female preponderance with $52 \%$ cases in female.
Tetralogy of Fallot according to natural history usually presents late and has favorable natural history, which can be the reason that it is the most common cyanotic CHD encountered in our study. TOF prevalence is known to be higher for Asian populations. ${ }^{3}$ A study in Atlanta, USA (19982005), reported a prevalence of $0.47 / 1000 .{ }^{3}$ In this study $38(7 \%)$ cases were of TOF. Among other cyanotic CHD, our findings are comparable with Saxena et al ${ }^{9}$. And Abquari et al. ${ }^{10}$ Although most Asian studies reported a relatively high incidence of PS, we15 cases $(2.7 \%)$. Nonetheless, this study results match the incidence of PS in other Indian hospital-based studies in Mysore, Kanpur, and Mumbai. ${ }^{8,35}$

Hypoplastic left heart syndrome (HLHS) shows a prevalence of $1.5-2.8$ per 1000 live births in the USA (2.3 in the Atlanta study) and 0.62 per 1000 in Taiwan. ${ }^{36,37}$ In India, frequency is low $(0.49 \%)$. In this study we found $2(0.7 \%)$ cases and both in male gender. Both cases presented below age of 1 month. We identified low prevalence of CoA, TAPVC and EA 5 (0.9\%) each and AS 11(2\%), which matches earlier reports of low prevalence in Asian countries. ${ }^{7,38}$ Prevalence of other cardiac defects were PA 22 (4\%), TGA 15 (2.7\%), TA 12 (2.2), DORV 11 (2\%), Truncus arteriosus 3(0.5).

A higher incidence of complex CHDs has been reported in Asian infants. ${ }^{37}$ Recent study from Pakistan reported a similarly high incidence of complex CHDs. ${ }^{2}$ Parent consanguinity has been suggested as a possible cause of increased incidence of complex CHDs. In the present study complex heart diseases were found in $5(0.9 \%)$ cases.

The high frequency of acyanotic lesions in most studies was probably an overestimation of septal defects like VSDs and ASDs, which may spontaneously close during the postnatal growth period. Hence, long-term follow up of patients below 5 years is required for more accurate estimation.

Although 73127 patients were screened which is huge, still there were many limitations. The primary limitation of our study was that data for 
the mortality of undiagnosed CHD patients in primary care centres were not available. Therefore, in such population- based prevalence studies, the involvement of primary care centres should be considered important. Other limitation was short study period and limited resources. The absence of any major cardiac centre in Odisha and the east part of India shifts the major portion of peripherally diagnosed cases to other cardiac centres of India.

\section{Conclusion}

The aim of this dissertation was to contribute new insight to the area of prevalence of congenital heart disease in Western Odisha. It was also aimed to compare the different characteristics of congenital heart disease in our study place to the rest of country. Primary health care centres in India are not adequately equipped to detect CHDs. Spreading awareness and improving the methods of prenatal diagnosis for these defects may ameliorate this. Prevalence of CHD varies in wide range depending upon the population and diagnostic tool. For better estimation of prevalence, more elaborate community-based studies that include fetal diagnosis as well as examination of patients from newborn to adult are needed. Research should focus on birth prevalence of congenital heart disease in newborn to know the actual no of newborn present with CHD.

\section{Author's Contribution}

JNB has developed the concept proposal, manuscript writing and literature search. SKS worked on definition of intellectual content, contents and literature search. SK has done the statistical analysis, manuscript writing, literature search, data collection and validation. AK and BNS has done the data collection and data entry. All the authors have done the proof reading.

\section{Acknowledgement}

We are thankful to our Head of department, Consultants of Dept of Pediatric and Dept of Cardiology and Colleagues who have continuously encouraged us and at last but not least, the patients without whom this study would not have been possible.

\section{Conflict of Interest}

The authors declared that they have no conflicts of interest.

\section{References}

1. Marelli AJ, Ionescu-Ittu R, Mackie AS, Guo L, Dendukuri N, Kaouache M. Lifetime prevalence of congenital heart disease in the general population from 2000 to 2010. Circulation 2014; 130(9): 749-56.

2. Dolk H, Loane M, EUROCAT Steering Committee. Congenital Heart Defect in Europe: 2000-2005. Newtownabbey, Northern Ireland: University of Ulster; March 2009. Available from: http://eurocat.biomedical.co.uk/content/Sp ecial-Report.pdf. Accessed May18, 2017.

3. Hoffman JIE. Incidence of congenital heart disease: I. Postnatal incidence. Pediatr Cardiol. 1995;16:103-13.

4. Sommer RJ, Hijazi ZM, Rhodes JF Jr. Pathophysiology of congenital heart disease in the adult: Part I: Shunt lesions. Circulation 2008;117:1090- 9.

5. Van der Linde D, Konings EE, Slager MA, Witsenburg M, Helbing WA, Takkenberg $\mathrm{JJ}$, et al. Birth prevalence of congenital heart disease worldwide: a systematic review and meta-analysis. J Am Coll Cardiol 2011;58(21):2241-7.

6. Suzanne M Jason L. Salemi Nembhard WN, Fixler DE, Correa A Mortality Resulting From Congenital Heart Disease Among Children and Adults in the United States, 1999 to 2006.Circulation 2010; 122(22):2254-63.

7. Gupta I, Gupta ML, Parihar A, Gupta CD. Epidemiology of rheumatic and congenital heart diseases in school children. J Indian Med Assoc 1992;90:57- 9 
8. Vashishtha VM, Kalra A, Kalra K, Jain VK. Prevalence of congenital heart disease in school children. Indian Pediatr 1993;30:1337- 40.

9. Saxena A. Congenital heart disease in India: A status report. Indian J Pediatr 2005;72:595- 8 .

10. Smitha R, Karat SC, Narayanappa D, Krishnamurthy B, Prasanth SN, Ramachandra NB. Prevalence of congenital heart diseases in Mysore. Indian J Hum Genet 2006;12:11- 6.

11. Khalil A, Aggarwal R, Thirupuram S, Arora R. Incidence of congenital heart disease among hospital live births in India. Indian Pediatr 1994;31:519- 27

12. Kapoor R, Gupta S. Prevalence of congenital heart disease, Kanpur, India. Indian Pediatr 2008;45:309- 11.

13. Lawn JE, Cousens S, Zupan J; Lancet Neonatal Survival Steering Team. 4 million neonatal deaths: When? Where? Why? Lancet 2005;365:891- 900

14. Wren C, O'Sullivan JJ. Survival with congenital heart disease and need for follow up in adult life. Heart 2001;85: 438- 43.

15. Warnes CA, Liberthson R, Danielson GK, Dore A, Harris L, Hoffman JI, et al. Task force 1: The changing profile of congenital heart disease in adult life. $\mathrm{J}$ Am CollCardiol 2001;37:1170- 5

16. Bairwa M, Rajput M, Sachdeva S. Modified Kuppuswamy's socioeconomic scale: Social researcher should include updated income criteria, 2012. Indian J Community Med 2013;38:185- 6.

17. Kisslo J, Byrd BF, Greiser EA, Gresser C, Gillam LD, Ivy W, et al. Recommendations of continuous quality improvement in echocardiography. J Am Echocardiogr 1995;8:1-28.

18. Bernier PL, Stefanescu A, Samoukovic G, Tchervenkov CI. The challenge of congenital heart disease worldwide: epidemiologic and demographic facts. Semin Thorac Cardiovascsurg Pediatr Card Surg Annu. 2010;13:26-34.

19. Abqari S, Gupta A, Shahab T, Rabbani MU, Ali SM, Firdaus U, et al. Profile and risk factors for congenital heart defects: A study in a tertiary care hospital. Ann Pediatr Cardiol 2016;9:216- 21.

20. Hussain M, Tahura S, Sayeed MA, Rahman MM, Kar SK. Past and present pattern of congenital heart disease at DSH: A situation analysis. Bangladesh J Child Health 2010;34:51- 5.

21. Finnemore A, Groves A. Physiology of the fetal and transitional circulation. Semin Fetal Neonatal Med. 2015 Aug;20(4):2106.

22. Patricia Y. Chu, Jennifer S. Li. Congenital Heart Disease in Premature Infants 25-32 Weeks Gestational Age, PlumX Metrics, The Journal of pediatrics, SN: 1097-6833, Vol: 181, Page: 37-41.e1. available from https://www.jpeds.com/article/S00223476(16)31101-5/abstract

23. Wren $\mathrm{C}$, Irving CA, Griffiths JA, O'Sullivan JJ, Chaudhari MP, Haynes SR, Smith JH, Hamilton JR, Hasan A: Mortality in infants with cardiovascular malformations. Eur J Pediatr. 2012, 171: 281-287. 10.1007/s00431-011-1525-3.

24. Honein MA, Kirby RS, Meyer RE, Xing J, Skerrette NI, Yuskiv N, Marengo L, Petrini JR, Davidoff MJ, Mai CT, Druschel CM, Viner-Brown S, Sever LE, National Birth Defects Prevention Network: The association between major birth defects and preterm birth. Matern Child Health J. 2009, 13: 164-175. 10.1007/s10995-008-0348-y.

25. Wren C: Prematurity, low birth weight, and cardiovascular malformations. Pediatrics. 2011, 127: 385-386. 10.1542/peds.2010-3345.

26. Schoenwolf G, Bleyl S, Brauer P, FrancisWest P. Development of the Heart Larsen's 
Human Embryology. Philadelphia, PA: Churchill Livingstone; 2015. pp. 267-303.

27. Sadler T. Cardiovascular System. In: Sadler T, editor. Langman's Medical Embryology. 13. Philadelphia, PA: Wolters Kluwer; 2015. pp. 175-217.

28. Saxena A, Mehta A, Sharma M, Salhan S, Kalaivani M, Ramakrishnan S, et al. Birth prevalence of congenital heart disease: A cross sectional observational study from North India. Ann Pediatr Cardiol. 2016;9: 205-9.

29. Wanni KA, Shahzad N, Ashraf M, Ahmed K, Jan M, Rasool S. Prevalence and spectrum of congenital heart diseases in children. Heart India 2014;2:76- 9.

30. Misra M, Mittal M, Verma AM, et al. Prevalence and pattern of congenital heart disease in school children of eastern Uttar Pradesh. Indian Heart J. 2009;61:58-60.

31. Thakur JS, Negi PC, Ahluwalia SK, Sharma R, Bhardwaj R. Congenital heart disease among school children in Shimla hills. Indian Heart J. 1995;47:232-235.

32. Chadha SL, Singh N, Shukla DK. Epidemiological study of congenital heart disease. Indian J Pediatr. 2001;68:507510 .

33. Ashraf M, Chowdhary J, Khajuria K, Reyaz AM. Spectrum of congenital heart disease in Kashmir, India. Indian Pediatr. 2009;46:1107-1108.

34. Bhat NK, Dhar M, Kumar R, Patel A, Rawat A, Kalra BP. Prevalence and pattern of congenital heart disease in Uttarakhand, India. Indian J Pediatr. 2013;80:281-285.

35. Mitchell SC, Korones SB, Berendes HW. Congenital heart disease in 56,109 births. Incidence and natural history. Circulation 971;43:323- 32 .
36. Oyen N, Poulsen G, Boyd HA, Wohlfahrt J, Jensen PK, Melbye M. National time trends in congenital heart defects, Denmark, 1977-2005. Am Heart J. 2009; 157:467-473.

37. $\mathrm{Wu} \mathrm{MH}$, Chen $\mathrm{HC}$, Lu CW, Wang JK, Huang SC, Huang SK. Prevalence of congenital heart disease at live birth in Taiwan. J Pediatr. 2010;156:782-785.

\section{List of Abbreviations}

M : Months

TA* : Truncus arteriosus

Yr : Years

ECD : Endocardial cushion defect

SES : Socio Economic Status

HLHS : Hypoplastic left heart syndrome

Echo : Echocardiography

$\mathrm{S}_{2} \quad$ : Second heart sound

$\mathrm{SpO}_{2}$ :Oxygen Saturation of peripheral blood

LMIC : Low- and middle-income countries

OPD : Out-patient department

IPD : In-patient department.

CHD : Congenital heart disease

VSD : Ventricular septal defect

ASD : Atrial septal defect

PDA : Patent ductus arteriosus

AS : Aortic stenosis

PA : Pulmonary atresia

TOF : Tetralogy of Fallot

TGA : Transposition of great arteries

PS : Pulmonary stenosis

TAPVC: Total anomalous pulmonary venous connection

COA : coarctation of aorta

TA : tricuspid atresia

EA : Ebstein anomaly

DORV : Double- outlet right ventricle

BAV : Bicuspid aortic valve 